\title{
BMJ Open Early perceptions and behavioural responses during the COVID-19 pandemic: a cross-sectional survey of UK adults
}

\author{
Christina Atchison (10 ,' Leigh Robert Bowman (1) ," Charlotte Vrinten, ${ }^{3}$ \\ Rozlyn Redd, ${ }^{1}$ Philippa Pristerà, ${ }^{1}$ Jeffrey Eaton, ${ }^{2}$ Helen Ward ${ }^{1,2}$
}

To cite: Atchison C, Bowman LR, Vrinten C, et al. Early perceptions and behavioural responses during the COVID-19 pandemic: a cross-sectional survey of UK adults. BMJ Open 2021;11:e043577. doi:10.1136/ bmjopen-2020-043577

- Prepublication history and additional materials for this paper are available online. To view these files, please visit the journal online (http://dx.doi. org/10.1136/bmjopen-2020043577).

Received 07 August 2020 Revised 11 December 2020 Accepted 20 December 2020

\section{Check for updates}

(C) Author(s) (or their employer(s)) 2021. Re-use permitted under CC BY-NC. No commercial re-use. See rights and permissions. Published by BMJ.

For numbered affiliations see end of article.

\section{Correspondence to} Dr Christina Atchison; christina.atchison11@imperial. ac.uk

\section{ABSTRACT}

Objective To examine risk perceptions and behavioural responses of the UK adult population during the early phase of the COVID-19 epidemic in the UK.

Design A cross-sectional survey.

Setting Conducted with a nationally representative sample of UK adults within 48 hours of the UK Government advising the public to stop non-essential contact with others and all unnecessary travel.

Participants 2108 adults living in the UK aged 18 years and over. Response rate was $84.3 \%$ (2108/2500). Data collected between 17 March and 18 March 2020.

Main outcome measures Descriptive statistics for all survey questions, including number of respondents and weighted percentages. Robust Poisson regression used to identify sociodemographic variation in: (1) adoption of social distancing measures, (2) ability to work from home, and (3) ability and (4) willingness to self-isolate.

Results Overall, 1992 (94.2\%) respondents reported at least one preventive measure: $85.8 \%$ washed their hands with soap more frequently; $56.5 \%$ avoided crowded areas and $54.5 \%$ avoided social events. Adoption of social distancing measures was higher in those aged over 70 years compared with younger adults aged 18-34 years (adjusted relative risk/aRR: 1.2; 95\% Cl: 1.1 to 1.5). Those with lowest household income were three times less likely to be able to work from home (aRR: $0.33 ; 95 \% \mathrm{Cl}: 0.24$ to 0.45 ) and less likely to be able to self-isolate (aRR: 0.92; $95 \% \mathrm{Cl}: 0.88$ to 0.96 ). Ability to self-isolate was also lower in black and minority ethnic groups (aRR: $0.89 ; 95 \% \mathrm{Cl}$ : 0.79 to 1.0 ). Willingness to self-isolate was high across all respondents.

Conclusions Ability to adopt and comply with certain non-pharmaceutical interventions (NPIs) is lower in the most economically disadvantaged in society. Governments must implement appropriate social and economic policies to mitigate this. By incorporating these differences in NPIs among socioeconomic subpopulations into mathematical models of COVID-19 transmission dynamics, our modelling of epidemic outcomes and response to COVID-19 can be improved.

\section{INTRODUCTION}

On 31 December 2019, Chinese authorities notified the WHO of an outbreak of
Strengths and limitations of this study

Nationally representative sample of the UK adult population.

- Quick data collection during a rapidly evolving public health emergency.

- Timeliness in relation to changing government response and recommendations.

- The online approach excludes those without internet access.

- Collecting self-reported data is generally subject to limitations including honesty, introspective ability and interpretation of the questions.

pneumonia in Wuhan City, which was later classified as a new disease: COVID-19. ${ }^{1}$ Following identification of cases in countries outside China, on 30 January 2020, the WHO declared the outbreak of COVID-19 a 'Public Health Emergency of International Concern'. ${ }^{1}$ In the UK, the first cases of COVID-19 were diagnosed at the end of January 2020, and community transmission was reported a few weeks later. ${ }^{23}$ Government measures to control the epidemic were first announced on 22 January 2020 and included travel advice, information for those returning from affected countries, testing of suspected cases, isolation and contact tracing. This was followed in early February by a public health information campaign advising people to adopt hygiene measures to protect themselves and others, including more frequent handwashing with soap and water, using hand sanitiser if soap and water are not available, and covering mouth and nose with a tissue or sleeve when coughing or sneezing. ${ }^{4}$ Then, on 3 March 2020, the UK Government published its action plan setting out the UK-wide response to the novel coronavirus. The UK Government's response outlined measures in four key areas: containing the outbreak, 
delaying its spread, mitigating the impact, and research to improve diagnostics and treatment. ${ }^{5}$

On 16 March 2020, 5 days after the WHO declared the outbreak of COVID-19 a pandemic, the UK Prime Minister announced a shift to the delay phase of the UK response with measures aimed at suppressing the spread of the infection in the population through nonpharmaceutical interventions (NPIs), including social distancing of the whole population, isolation of cases for 7 days and quarantine of their household members for 14 days. ${ }^{6}$ The public was advised to stop non-essential contact with others and all unnecessary travel: including working from home where possible and avoiding pubs, theatres, restaurants and other social venues. ${ }^{6}$ This shift in response was prompted by a mathematical modelling study which showed that a combination of social distancing of the entire population, home isolation of cases and household quarantine of their family members (and possible school and university closure) was required to suppress transmission to a level that would enable the National Health Service to cope with the surge in cases requiring hospital admission and ventilation. ${ }^{7}$

The effect of NPIs to reduce transmission rates is dependent on compliance with public health advice on social distancing. In the initial stages of the UK epidemic, this advice was voluntary, and not enforced by the government. This was criticised due to concern that measures may not have the desired impact if a significant proportion of the population were unable or unwilling to comply.

Protective behaviours are not uniformly adopted throughout a population during an epidemic. Evidence from influenza outbreaks suggests that women are more likely to adopt NPIs than men. ${ }^{8}$ In the UK, during the H1N1 pandemic, non-white ethnic groups were more likely to adopt hygiene and social distancing behaviours compared with white. ${ }^{10}{ }^{11}$ Employment status has also been associated with NPI adoption. ${ }^{12}{ }^{13}$ Evidence from Australia during the H1N1 pandemic found those who were self-employed and who were unable to work from home were most likely to report intentions to not comply with preventative measures ${ }^{13}$ suggesting that without support, it may be challenging for individuals who are unable to work from home to comply with certain public health recommendations. During the current COVID-19 pandemic, public risk perceptions and knowledge have been explored in various countries. ${ }^{14-20}$ However, only a few have identified the factors associated with greater adoption of preventative measures, or how these associations vary by context. In Hong Kong, both greater understanding of COVID-19 and increased anxiety were associated with greater adoption of social distancing behaviours. ${ }^{18}$

As such, this study aimed to assess reported behaviour and intention to comply with the NPIs, as recommended by the UK Government at the time of the survey. Preliminary findings were shared with the Scientific Advisory Group for Emergencies, which advises the UK Government's response to COVID-19. ${ }^{21}$

\section{METHODS}

\section{Study design and sample}

A cross-sectional survey of a nationally representative sample of the UK adult (aged 18 years and over) population was conducted between 17 March and 18 March 2020, which followed the UK Government's 16 March announcement to increase social distancing measures by advising the public to stop non-essential contact with others and all unnecessary travel. ${ }^{6}$

The online survey was administered by YouGov, a market research company, to members of its UK panel of $800000+$ individuals. ${ }^{22}$ This panel includes individuals who have specifically opted in to participate in online research activities. YouGov actively recruits hard-to-reach individuals to this panel (such as younger people and those from ethnic minorities) via a network of partners with specific experience in recruiting these audiences for online activities or with access to a wide range of online sources that cater to these groups.

A sample of 2108 adults was achieved through nonprobabilistic quota sampling. ${ }^{22}$ Emails were sent to 2500 panellists from the base sample, randomly selecting panellists with particular age, sex, ethnicity and UK geographical region of residence characteristics to achieve quotas that matched the proportions of people with those characteristics in the UK 2011 census data. ${ }^{23}$ The response rate was $84.3 \%(2108 / 2500)$. No incentive was given to participate in the survey.

\section{Survey instrument}

The questionnaire was adapted from a survey used in a similar study conducted in Hong Kong. ${ }^{24}$ The questionnaire had four components: (1) sociodemographic characteristics, (2) risk perceptions towards COVID-19, (3) preventive behaviours, and (4) ability and willingness to self-isolate.

\section{Sociodemographic characteristics}

Sociodemographic characteristics consisted of sex, age, ethnicity, marital status, caring responsibilities, UK area of residence and socioeconomic status (SES). SES was assessed using five indicators: education level, employment status, household income, savings and household tenure.

\section{Risk perceptions towards COVID-19}

Risk perceptions towards COVID-19 were measured by perceived susceptibility and perceived severity. Susceptibility was measured by asking respondents about perceived likelihood of being infected with COVID-19 under the UK Government's current preventive measures. Severity was measured by asking respondents about perceived seriousness of symptoms if they were infected with COVID-19.

\section{Preventive behaviours}

Preventive behaviours included information on perceived effectiveness and actual adoption of preventive behaviours (to protect oneself and others), to prevent both contracting COVID-19 and onward transmission, 
and were collected under three categories: (1) hygiene practices (wearing a face mask, washing hands more frequently with soap and water, using hand sanitiser more regularly, disinfecting the home, covering nose and mouth when sneezing or coughing); (2) travel avoidance (travel to affected countries and travel to areas inside and outside the UK, regardless of whether they were affected); (3) social distancing (avoiding public transport, social events, going out in general, going to hospital or other healthcare settings, crowded places, and contact with people who have a fever or respiratory symptoms).

\section{Willingness to self-isolate}

Willingness to self-isolate was measured by asking respondents whether, if advised by a healthcare professional, they would be willing to self-isolate. Similarly, ability to self-isolate was measured by asking respondents whether, if advised by a healthcare professional, they would be able to self-isolate.

At the time the survey was conducted, Public Health England's operational definition of 'self-isolation' was 'if you have symptoms of coronavirus infection (COVID19), however mild, do not leave your home (even to buy food or essentials) or have any visitors for 7 days from when your symptoms started. This includes not going to work, school or other public places, and avoiding public transport or taxis. Self-isolation is the same as voluntary quarantine. ${ }^{, 25}$

We worked with YouGov to optimise question clarity and ease of understanding for the UK population.

The survey instrument is freely available to download from the School of Public Health, Imperial College London COVID-19 resources webpage: http:// www.imperial.ac.uk/medicine/departments/schoolpublic-health / infectious-disease-epidemiology/ mrc-global-infectious-disease-analysis / COVID-19/ covid-19-scientific-resources/.

\section{Data collection}

Data were collected between 16:30 GMT on 17 March 2020 and 10:30 GMT on 18 March 2020. Participants identified for the sample were sent an email with a survey link. YouGov returned the anonymised data set to the Imperial College London research team for analysis.

\section{Data analysis}

Analyses were conducted in Stata V.15 and SPSS V.25.

Descriptive statistics for all variables present the number of respondents and the weighted percentages. Percentages were weighted for age, sex, region and ethnicity to account for variation in response rates, so as to be representative of the population (18+ years) of the UK. Details of the weighting approach used and the sample population profile are in the online supplemental file S1.

For analysis, age, collected as discrete count in years, was collapsed into four age bands routinely used in the UK to report COVID-19-related data. Ethnicity data were collected using the 18 response categories used in the
UK 2011 census $^{23}$ but were collapsed into two categories (white/Black, Asian and minority ethnic (BAME)) because of small numbers of respondents in BAME groups.

Robust Poisson regression, by estimating relative risk (RR), was used to identify sociodemographic variation in: (1) adoption of social distancing measures, (2) ability to work from home, and (3) ability and (4) willingness to self-isolate. Adoption of social distancing measures was proxied by respondents reporting to have avoided crowded places and social events to protect themselves or others from COVID-19. For our outcomes of interest, an RR $>1$ indicated that the group was more likely to (1) adopt social distancing measures, (2) be able to work from home, and (3) be able and (4) willing to self-isolate relative to the reference group for that independent variable.

Age and sex were retained in all the regression models as they are considered important confounders. Including as many explanatory variables as possible can dilute true associations and lead to large SEs with wide and imprecise CIs, or, conversely, identify spurious associations. ${ }^{26}$ The conventional technique is to first run the univariate analyses and then use only those variables which meet a preset cut-off for significance to run a multivariable model. ${ }^{26}$ This cut-off is often more liberal than the conventional cut-off for significance (eg, $\mathrm{p}<0.20$, instead of the usual $\mathrm{p}<0.05)$ since its purpose is to identify potential predictor variables rather than to test a hypothesis. ${ }^{26}$

Therefore, only variables that appeared to be associated $(\mathrm{p}<0.20)$ in the unadjusted analyses were considered in the adjusted analyses. Adjusted RR (aRR) and 95\% CIs were estimated. Associations with a $p$ value of $<0.05$ in the adjusted analyses were considered to be statistically significant. We did not adjust our $\mathrm{p}$ values for multiple comparisons to reduce type I errors for null associations because this increases type II errors for those associations that are not null. ${ }^{27}$ Not adjusting for multiple comparisons in the context of this study is preferable because it will result in less errors of interpretation as the data under examination are not random numbers but actual observations on people. Furthermore, in the context of a global pandemic caused by an emerging infectious disease, it may be better to explore leads that may turn out to be wrong than risk missing possibly important findings that could provide insights for control of the virus.

We tested for collinearity between education level, employment status, household income, savings and household tenure. For these categorical variables, collinearity was measured by examining bivariate relationships using Pearson's $\mathrm{X}^{2}$ tests. Where collinearity was detected, we ran separate adjusted regression analyses for those variables, using only other explanatory variables in those models that were not strongly correlated.

\section{Patient and public involvement}

Prior to conducting the study, we distributed an online feedback form to communities across the UK using local networks of public partners and contacts, Twitter and via 
VOICE-global.org, an online platform for public involvement in research established by Newcastle University. We received 420 responses, including 328 from members of the public. The experiences and feedback shared guided our study design and scope, including the phrasing of the survey tool's closed-ended questions and the refinement of pre-populated answer choices.

Study results will be shared with the public both by posting on the VOICE-global.org news page, on the research team's website, and through direct mail with those who consented to be contacted about our research and involvement activity.

\section{RESULTS}

The overall sample is described in table 1 . There was lower response among people from minority ethnic groups and older age groups compared with the UK population profile (online supplemental file S1 for full details of the sample profile compared with UK population profile). In summary, of the 2108 respondents, $11.1 \%$ were $18-24$ years old, and $13.5 \%$ were 70 years or older. The majority of respondents were white $(93.9 \%)$. In total, $43.4 \%$ were in full-time work and $14.1 \%$ were in part-time work.

Overall, $77.4 \%$ (1640/2108) of respondents reported being worried about the COVID-19 outbreak in the UK. None of the 2108 respondents had previously tested positive for COVID-19, and $47.5 \%$ (979/2108) believed that it was likely they would be infected at some point in the future under the UK Government's preventive measures. If infected, just over half (56.9\%) of respondents would expect to be moderately severely affected (eg, may need self-care and rest in bed) (table 1 ).

Accordingly, $94.2 \%$ of adults reported taking at least one preventive measure (to protect oneself and others) against COVID-19 infection: $85.8 \%$ washed their hands with soap more frequently; $56.5 \%$ avoided crowded areas; $54.5 \%$ avoided social events and $39.2 \%$ avoided public transport (figure 1). Most reported that their behavioural change was in response to government guidance $(71.3 \%)$. Preventive measures perceived to be most effective were washing hands more frequently with soap and water $(92.5 \%)$, avoiding contact with people who have a fever or respiratory symptoms (91.4\%), and covering nose and mouth when sneezing or coughing $(90.0 \%)$ (figure 1). Perceived effectiveness of preventive measures was higher than actual adoption for all measures. This was particularly marked for social distancing measures (figure 1).

\section{Adoption of social distancing measures}

Overall, $45.2 \%$ of respondents reported adopting social distancing measures (avoiding crowded places and avoiding social events) to protect themselves or others from COVID-19.

Table 2 shows the regression analysis results for adoption of social distancing measures. Being 70 years or older (64.2\% vs $38.4 \%$; aRR: 1.2 ; $95 \%$ CI: 1.1 to 1.5 ) was positively associated with greater adoption compared
Table 1 Demographics, socioeconomic characteristics and COVID-19 risk perceptions, $\mathrm{N}=2108$

\begin{tabular}{|c|c|c|}
\hline Characteristic & No & Weighted \% \\
\hline \multicolumn{3}{|l|}{ Demographic and socioeconomic } \\
\hline \multicolumn{3}{|l|}{ Age (years) } \\
\hline $18-24$ & 218 & 11.1 \\
\hline $25-34$ & 294 & 14.4 \\
\hline $35-44$ & 396 & 19.3 \\
\hline $45-54$ & 355 & 17.5 \\
\hline $55-69$ & 519 & 24.2 \\
\hline 70 or above & 326 & 13.5 \\
\hline \multicolumn{3}{|l|}{ Sex } \\
\hline Male & 987 & 48.0 \\
\hline Female & 1094 & 50.7 \\
\hline Prefer not to say & 27 & 1.3 \\
\hline \multicolumn{3}{|l|}{ Ethnicity } \\
\hline White group & 1985 & 93.9 \\
\hline Asian/Asian British & 48 & 2.4 \\
\hline $\begin{array}{l}\text { Black/African/Caribbean/Black } \\
\text { British }\end{array}$ & 20 & 1.0 \\
\hline $\begin{array}{l}\text { Other ethnic group, including } \\
\text { mixed/multiple ethnic groups }\end{array}$ & 39 & 1.9 \\
\hline Prefer not to say & 16 & 0.77 \\
\hline \multicolumn{3}{|l|}{ Marital status } \\
\hline $\begin{array}{l}\text { Married, civil partnership or living } \\
\text { as married }\end{array}$ & 1283 & 60.3 \\
\hline Separated, divorced or widowed & 270 & 12.2 \\
\hline Never married & 545 & 27.1 \\
\hline Prefer not to say & 10 & 0.45 \\
\hline \multicolumn{3}{|l|}{ Area of residence } \\
\hline London & 239 & 13.1 \\
\hline North & 522 & 23.3 \\
\hline Midlands & 531 & 25.2 \\
\hline South & 485 & 22.5 \\
\hline Northern Ireland, Scotland, Wales & 331 & 15.9 \\
\hline
\end{tabular}

Education

\begin{tabular}{|c|c|c|}
\hline No formal qualification & 121 & 5.5 \\
\hline Secondary-level qualification & 859 & 42.1 \\
\hline $\begin{array}{l}\text { Post-secondary level, below } \\
\text { bachelor }\end{array}$ & 148 & 6.9 \\
\hline Bachelor level or above & 664 & 30.8 \\
\hline $\begin{array}{l}\text { Other technical, professional or } \\
\text { higher qualification }\end{array}$ & 245 & 11.2 \\
\hline Don't know & 32 & 1.6 \\
\hline Prefer not to say & 39 & 2.0 \\
\hline \multicolumn{3}{|l|}{ Employment status } \\
\hline Working full time & 889 & 43.4 \\
\hline Working part time & 292 & 14.1 \\
\hline
\end{tabular}




\begin{tabular}{|c|c|c|}
\hline Characteristic & No & Weighted \% \\
\hline Full-time student & 112 & 5.6 \\
\hline Retired & 553 & 23.6 \\
\hline Unemployed or not working & 207 & 10.5 \\
\hline Other & 55 & 2.8 \\
\hline \multicolumn{3}{|l|}{ Household income } \\
\hline$<£ 20000$ & 440 & 20.7 \\
\hline$£ 20000-£ 29999$ & 355 & 16.8 \\
\hline$£ 30000-£ 49999$ & 472 & 22.4 \\
\hline$£ 50000$ and over & 429 & 20.6 \\
\hline Don't know & 103 & 5.1 \\
\hline Prefer not to say & 309 & 14.4 \\
\hline \multicolumn{3}{|l|}{ Savings } \\
\hline Less than $£ 100$ & 278 & 13.6 \\
\hline$£ 100-£ 999$ & 242 & 11.8 \\
\hline$£ 1000-£ 4999$ & 305 & 14.5 \\
\hline$£ 5000-£ 24999$ & 359 & 16.6 \\
\hline$£ 25000$ or more & 359 & 16.6 \\
\hline Prefer not to say & 565 & 26.9 \\
\hline \multicolumn{3}{|l|}{ Housing tenure } \\
\hline Own-outright & 681 & 30.4 \\
\hline Own-mortgage/shared ownership & 639 & 30.8 \\
\hline Rent-private landlord & 319 & 15.6 \\
\hline $\begin{array}{l}\text { Rent-local authority/housing } \\
\text { association }\end{array}$ & 219 & 10.7 \\
\hline Live with parents, family or friends & 215 & 10.7 \\
\hline Other & 35 & 1.8 \\
\hline
\end{tabular}

\section{COVID-19 risk perceptions}

\begin{tabular}{lrr}
$\begin{array}{l}\text { Level of worry about the current } \\
\text { COVID-19 outbreak in the UK }\end{array}$ & \\
Worried & 1640 & 77.4 \\
Not worried & 14 & 21.9 \\
Don't know & 0.74 \\
Perceived susceptibility & & \\
Likely & 979 & 47.5 \\
\hline $\begin{array}{l}\text { Neither likely or unlikely } \\
\text { Unlikely }\end{array}$ & 547 & 26.2 \\
$\begin{array}{l}\text { Don't know } \\
\text { Perceived severity } \dagger\end{array}$ & 220 & 15.9 \\
$\begin{array}{l}\text { I would expect it to be life- } \\
\text { threatening }\end{array}$ & 103 & 4.7 \\
$\begin{array}{l}\text { I would expect it to be severe (eg, } \\
\text { may need care and treatment in } \\
\text { hospital) }\end{array}$ & & \\
$\begin{array}{l}\text { I would expect it to be moderate } \\
\text { (eg, may need self-care and rest } \\
\text { in bed) }\end{array}$ & 1180 & 56.9 \\
\hline
\end{tabular}

Continued

\begin{tabular}{lll} 
Table 1 Continued & & \\
\hline Characteristic & No & Weighted \% \\
\hline $\begin{array}{l}\text { I would expect it to be mild (eg, } \\
\text { can go about daily tasks normally) }\end{array}$ & 351 & 17.2 \\
$\begin{array}{l}\text { I would expect to have no } \\
\text { symptoms }\end{array}$ & 33 & 1.7 \\
Don't know & 110 & 5.3
\end{tabular}

*Under the UK government's current preventive measures (at the time of the study), how likely or unlikely do you think it is you will be infected with the coronavirus (COVID-19) at any point in the future?

†Please imagine you were infected with coronavirus (ie, COVID-19), which of the following do you think would best apply?

with younger adults aged 18-34 years. Compared with those who were married, in a civil partnership or living as married $(48.4 \%)$, respondents who were separated, divorced or widowed $(44.1 \%$; aRR: 0.75 ; $95 \%$ CI: 0.64 to 0.87 ) or never married (38.4\%; aRR: $0.74 ; 95 \%$ CI: 0.63 to 0.88 ) were less likely to have adopted social distancing measures to prevent transmission of COVID-19. Respondents with $£ 100$ savings or less were one-fifth less likely to have adopted social distancing measures compared with those with $£ 25000$ or more in savings $(43.5 \%$ vs $48.4 \%$; aRR: 0.83 ; $95 \%$ CI: 0.73 to 0.95 ) (table 2 ).

\section{Ability to work from home}

Overall, $44.3 \%$ of respondents reported being able to work from home (ie, permitted by their employer and have the necessary equipment to do their job from home).

Respondents who held post-secondary but below degree-level (47.7\%; aRR: 0.68; 95\% CI: 0.59 to 0.79$)$ and secondary or below level (29.4\%; aRR: 0.45 ; $95 \%$ CI: 0.39 to 0.53 ) education qualifications were less likely to be able to work from home compared with those educated to degree level (62.6\%) (table 2). As with educational level, there was a household income and savings gradient with ability to work from home. Those with the lowest household income $(<£ 20000)$ were three times less likely to be able to work from home compared with those with household incomes of $£ 50000$ and above $(22.7 \%$ vs $67.3 \%$; aRR: 0.33 ; $95 \%$ CI: 0.24 to 0.45$)$. Respondents with $£ 100$ savings or less were half as likely to be able to work from home compared with those with $£ 25000$ or more in savings ( $33.1 \%$ vs $59.9 \%$; aRR: $0.51 ; 95 \%$ CI: 0.39 to 0.67 ) (table 2). Compared with those who owned their home outright, those renting accommodation from a local authority or housing association were less likely to be able to work from home ( $18.2 \%$ vs $41.0 \%$; aRR: 0.45 ; 95\% CI: 0.28 to 0.73 ).

\section{Willingness and ability to self-isolate}

Overall, perceived ability (87.0\%) and willingness $(87.6 \%)$ to self-isolate for 7 days if asked by a healthcare professional were high.

In terms of sociodemographic associations, there was no effect of sex on perceived ability to self-isolate 


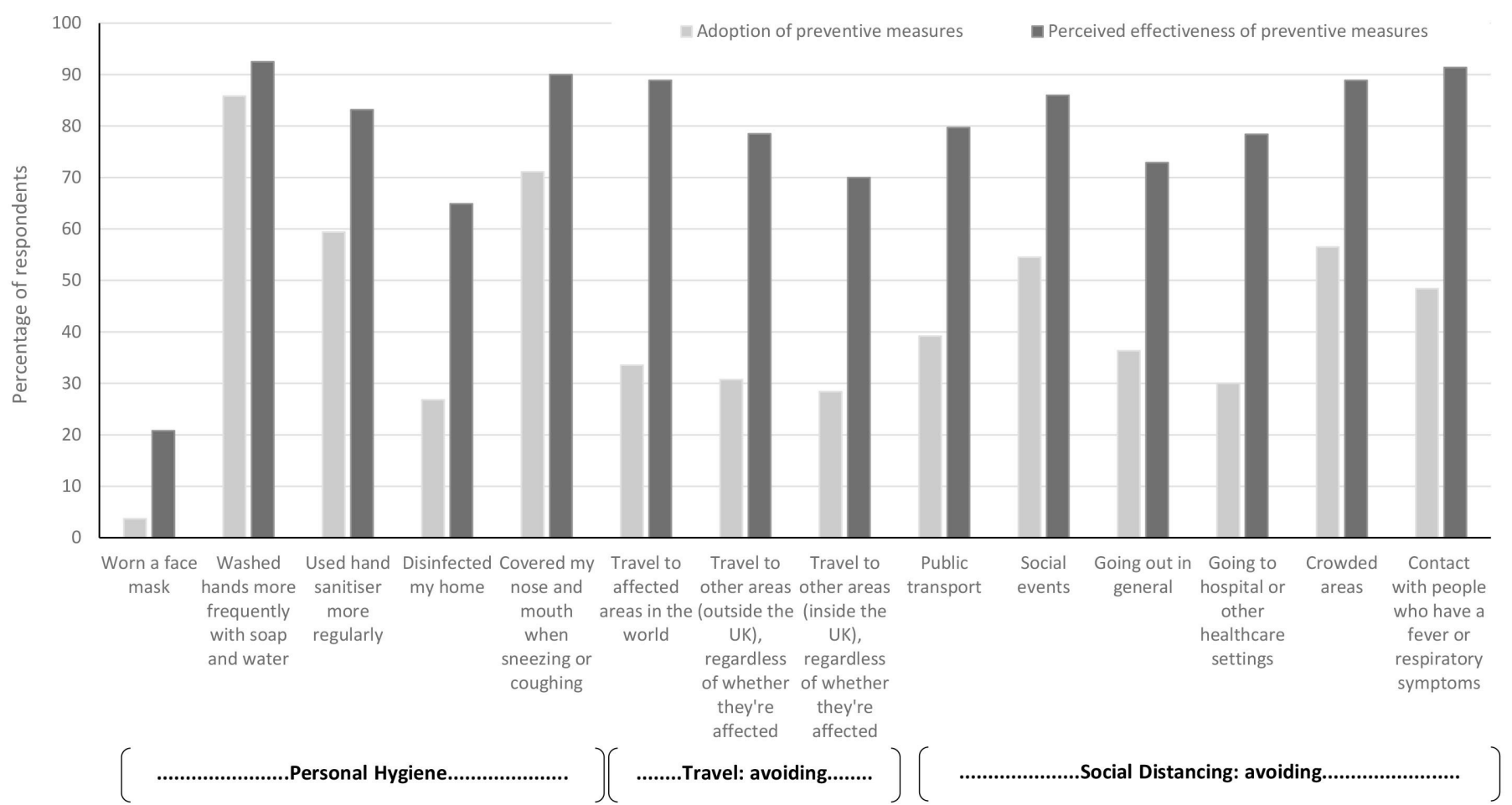

Figure 1 Perceived effectiveness and actual adoption of preventative measures to prevent transmission of COVID-19; N=2108.

(table 3). However, women were somewhat more willing to do so than men $(94.9 \%$ vs $91.8 \%$; aRR: $1.1 ; 95 \%$ CI: 1.0 to 1.2). Respondents from ethnic minority backgrounds perceived themselves to be less able to self-isolate than respondents from white backgrounds $(84.8 \%$ vs $92.1 \%$, aRR: 0.89 ; $95 \%$ CI: 0.79 to 1.0$)$, although they were equally willing to do so (table 3 ).

Some indicators of socioeconomic status were significantly associated with perceived ability and willingness to self-isolate. Respondents who held post-secondary but below degree-level education qualifications were less willing to self-isolate $(90.9 \%$ vs $94.9 \%$ aRR: $0.95 ; 95 \%$ CI: 0.92 to 0.99 ) than respondents educated to degree level (table 3). Those with household incomes below $£ 20000$ were less likely to be able to self-isolate compared with those on household incomes of $£ 50000$ and above ( $88.3 \%$ vs $95.5 \%$; aRR: 0.92 ; $95 \%$ CI: 0.88 to 0.96 ). Similarly, respondents with less than $£ 100$ in savings were less likely to be able to self-isolate compared with those with savings of $£ 25000$ or more (84.8\% vs $95.6 \%$; aRR: 0.90 ; $95 \%$ CI: 0.85 to 0.96 ). There was no effect on willingness to self-isolate by household income or amount of savings (table 3).

Those in accommodation rented from a private landlord, local authority or housing association were less likely to report being able to self-isolate, although this association was no longer significant when other sociodemographic factors were adjusted for. In terms of willingness to self-isolate, respondents renting accommodation from a local authority or housing association were less likely to be willing to self-isolate compared with those who owned their home outright (aRR: 0.94; 95\% CI: 0.89 to 0.99) (table 3).

\section{DISCUSSION}

This study reports on the perceptions and behaviour of the UK adult population in the 2 days following the UK Government's introduction of recommendations on social distancing on 16 March $2020 .{ }^{6}$ We found high levels of self-reported behavioural change. Notably, the most adopted measures, washing hands more frequently with soap and water, using hand sanitiser, and covering nose and mouth when sneezing or coughing, prominently featured in national public health campaigns from relatively early on in the epidemic, ${ }^{4}$ and mirror results seen in previous pandemics. ${ }^{29}$ However, there were marked differences between the perceived effectiveness and adoption of NPIs. This suggests that lack of knowledge on what measures are effective against COVID-19 is not a key driver of compliance in the UK population. In contrast, a similar study conducted in Hong Kong showed comparatively high-perceived effectiveness and adoption of preventive measures. ${ }^{24}$

Our results highlighted significant differences across demographic and socioeconomic strata for social distancing behaviour, ability to work from home, and the ability and willingness of people to self-isolate. There was a strong association between socioeconomic deprivation and ability to adopt NPIs. Although willingness to selfisolate was high overall, those from more disadvantaged backgrounds were less likely to be able to work from home or self-isolate if needed, suggesting the existence of structural barriers to adopting preventive behaviours in these groups. Specifically, our study found that those with less savings were the group least likely to adopt NPIs overall. As such, the barriers for this group appear the 


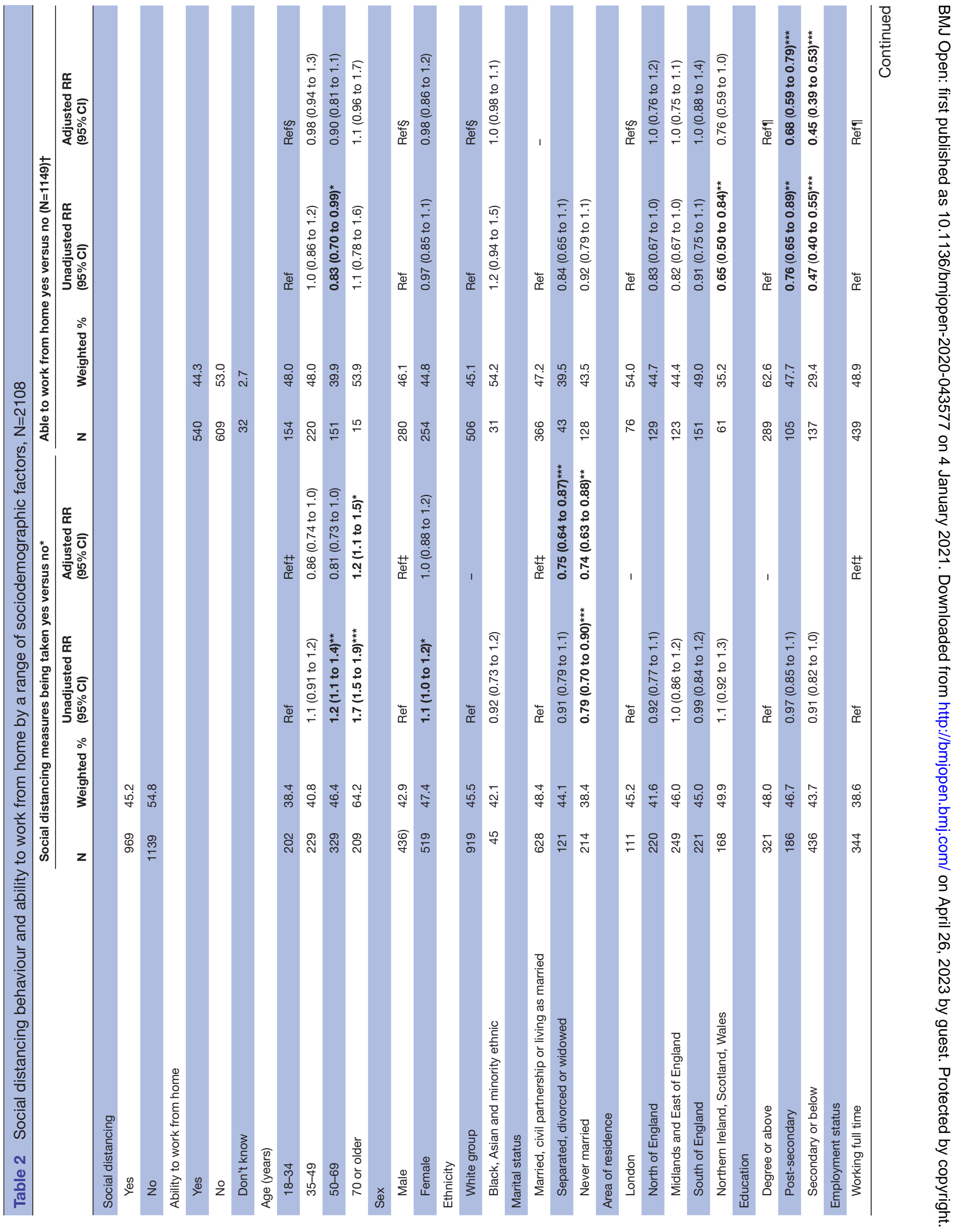




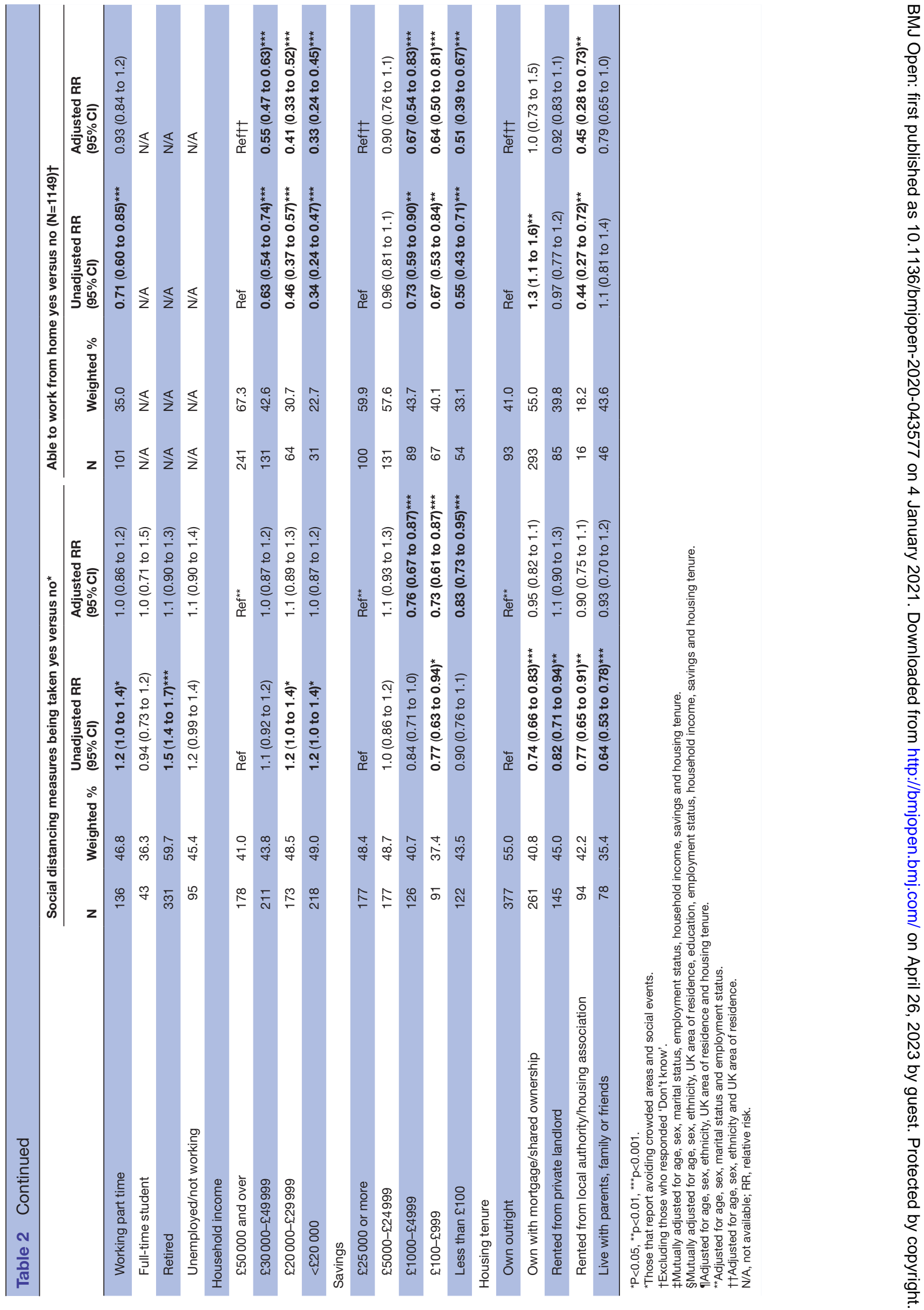




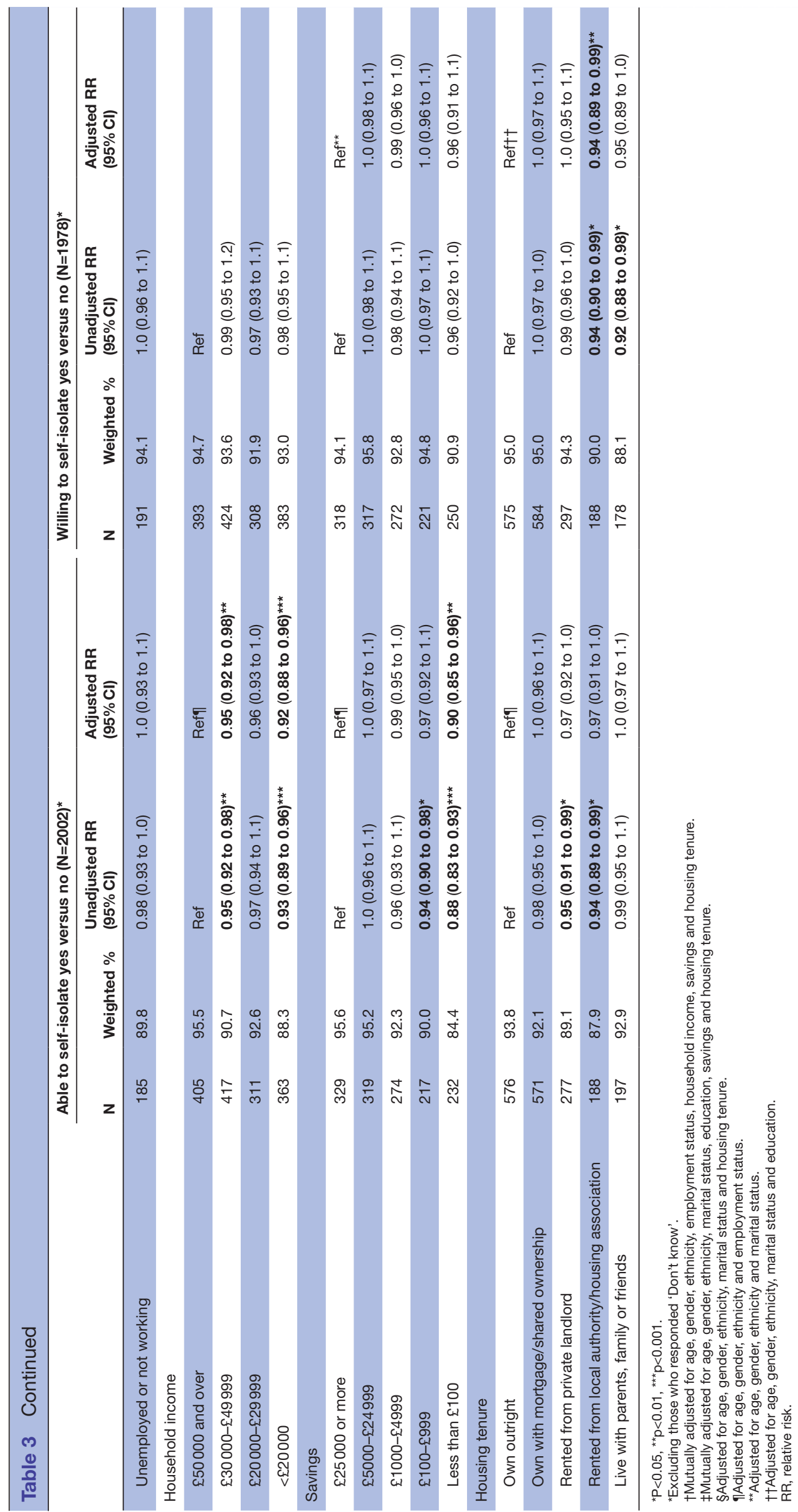


greatest. This is not surprising, as these individuals are likely to have less cushioning to withstand financial losses as a result of any NPIs that have a direct or indirect impact on employment or earnings.

The strength of this study is in the representative sample of the UK adult population, the ability to achieve our sample size quickly and the timeliness in relation to changing government recommendations. However, social distancing measures were only brought in 2 days before the survey. Therefore, there may have not been enough time for people to fully implement these measures prior to their participation in the study. But many employers had already begun allowing staff to work from home in the week prior to the UK Government's announcement, and ability and willingness to self-isolate do not measure behavioural change directly but intent. So, we believe our study does indeed measure attitudes and behaviours based on the most recent advice at the time of the survey. Social desirability bias is also possible given that participants were asked whether they were complying with government restrictions. However, this is less of an issue with online surveys where respondents are assured anonymity and answer questions in the privacy of their own home without any live human interaction. In addition, our sampling approach is prone to selection bias, for example by excluding participants without internet access and non-English speakers, and sampling from a panel of individuals who have specifically opted in to participate in online research activities. As in almost all population surveys, our study had unequal participation, with lower response among people from minority ethnic groups and older age groups. We reweighted the sample to account for such differential response, although this may not have overcome unknown participation biases. Furthermore, surveys collecting self-report data are generally subject to limitations including honesty, introspective ability and interpretation of the questions. The survey tool consisted of predominantly closed-ended questions. Thus, we were unable to explore responses in more depth.

Our findings highlight the stark choices faced by those in lower socioeconomic groups and suggest that unless the government intervenes to support these individuals, the impact of this epidemic will likely be felt unequally in our society. Not only this, but if a large proportion of the population continues to work while unwell, low compliance will render the various forms of social distancing less effective, as low-income workers are forced to choose between financial and physical health. Indeed, this behaviour has already been observed in the workplace in previous pandemics: workers without access to paid sick leave were more likely to work while unwell than those with paid sick leave. ${ }^{30}$ A study in China after the H7N9 epidemic found that only $7 \%$ of people reported willingness to self-quarantine. ${ }^{31}$ Also, during the Middle East respiratory syndrome outbreak in South Korea in 2015, there was heterogeneous uptake of preventive interventions. ${ }^{32}$

In the absence of a vaccine and treatments over the short term, high compliance with social distancing, selfisolation and household quarantine is paramount to reduce transmission and the impact of COVID-19. NPI compliance, risk perception and behaviour are not consistent across cultures, social status or time. Indeed, previous studies have shown that perceptions and behaviours often change over time. ${ }^{29}$ Therefore, current modelling projections of the impact of NPIs on morbidity and mortality are always provisional. ${ }^{7}$ Future COVID-19 models should explore the variation captured in this and previous studies to better estimate the impact of differential uptake of NPIs in the UK and beyond. It is also important to monitor behaviour throughout the epidemic to know when to implement further public health messaging, and when further or alternative government actions might be required, to mitigate falling compliance.

\section{Conclusions and policy implications}

Our findings highlight that those most economically disadvantaged in society are less able to comply with certain NPIs, likely in part due to their financial situation. While one approach may be to better tailor public health messaging to this subpopulation, this must be done alongside considered fiscal and monetary policy to mitigate the financial costs of following government public health advice. Therefore, it is imperative that the UK Government, and governments around the world, quickly develop and implement policies to support the most vulnerable, in a bid to minimise the long-term social and economic harm caused by COVID-19. Government policy should recognise the disparity in impact across socioeconomic groups, particularly across the labour market, and should aim to support workers equitably across the income spectrum. This would likely help increase compliance across the population to the levels required to suppress transmission and thereby reduce the strain on national health services, both in the UK and abroad. Although the UK Government has since announced a range of measures to support public services, individuals and businesses, in part to facilitate compliance with current lockdown measures,${ }^{33}$ it is uncertain how long these protections will be in place for and whether they will continue once lockdown restrictions are lifted.

\section{Author affiliations}

${ }^{1}$ Patient Experience Research Centre, School of Public Health, Imperial College London, London, UK

${ }^{2}$ MRC Centre for Global Infectious Disease Analysis and Abdul Latif Jameel Institute for Disease and Emergency Analytics (J-IDEA), School of Public Health, Imperial College London, London, UK

${ }^{3}$ Centre for Health Economics \& Policy Innovation, Department of Economics \& Public Policy, Imperial College Business School, Imperial College London, London, UK

Twitter Helen Ward @profhelenward

Acknowledgements The survey was conducted by YouGov on behalf of the Patient Experience Research Centre, School of Public Health, Imperial College London. Questions were developed by the authors, and YouGov provided suggestions to improve clarity and understandability. We thank Professor Kin On Kwok, Ms Wan In Wei, Professor Samuel Yeung Shan Wong and the research team in the Division of Infectious Diseases of JC School of Public Health and Primary Care, The Chinese University of Hong Kong, Hong Kong Special Administrative Region, China for permission to use their survey instrument and translating it into English. 
Contributors CA, LRB, RR, PP and HW designed the study. CA, JE and CV analysed the data and performed the statistical analyses. CA, LRB, RR, CV and HW drafted the initial manuscript. All authors reviewed the drafted manuscript for critical content and approved the final version. CA and HW are the guarantors.

Funding The study was supported by Imperial NIHR Research Capability Funding (Award No. P81291). HW is a National Institute for Health Research (NIHR) Senior Investigator (Award No. P75372).

Disclaimer The views expressed in this article are those of the authors and not necessarily those of the NHS, the NIHR or the Department of Health.

Competing interests None declared.

Patient consent for publication Not required.

Ethics approval The Imperial College London Research Ethics Committee approved the study (Ref 20IC5861). Informed consent was obtained from those who chose to complete the survey after having read introductory information on its content and purpose.

Provenance and peer review Not commissioned; externally peer reviewed.

Data availability statement Data are available upon reasonable request. The survey instrument is freely available to download from the School of Public Health, Imperial College London COVID-19 resources webpage: http://www.imperial.ac. uk/medicine/departments/school-public-health/infectious-disease-epidemiology/ mrc-global-infectious-disease-analysis/covid-19/covid-19-scientific-resources/ The data used for the analyses are available from the corresponding author on request.

Supplemental material This content has been supplied by the author(s). It has not been vetted by BMJ Publishing Group Limited (BMJ) and may not have been peer-reviewed. Any opinions or recommendations discussed are solely those of the author(s) and are not endorsed by BMJ. BMJ disclaims all liability and responsibility arising from any reliance placed on the content. Where the content includes any translated material, BMJ does not warrant the accuracy and reliability of the translations (including but not limited to local regulations, clinical guidelines, terminology, drug names and drug dosages), and is not responsible for any error and/or omissions arising from translation and adaptation or otherwise.

Open access This is an open access article distributed in accordance with the Creative Commons Attribution Non Commercial (CC BY-NC 4.0) license, which permits others to distribute, remix, adapt, build upon this work non-commercially, and license their derivative works on different terms, provided the original work is properly cited, appropriate credit is given, any changes made indicated, and the use is non-commercial. See: http://creativecommons.org/licenses/by-nc/4.0/.

\section{ORCID iDs}

Christina Atchison http://orcid.org/0000-0001-8304-7389

Leigh Robert Bowman http://orcid.org/0000-0003-0657-7911

\section{REFERENCES}

1 World Health Organisation. Rolling updates on coronavirus disease (COVID-19), 2020. Available: https://www.who.int/emergencies/ diseases/novel-coronavirus-2019/events-as-they-happen

2 ECDC. Coronavirus disease 2019 (COVID-19) pandemic: increased transmission in the EU/EEA and the UK - seventh update Stockholm, 2020.

3 Public Health England. Weekly coronavirus disease 2019 (COVID-19) surveillance report: summary of COVID-19 surveillance systems, 2020. Available: https://assets.publishing.service.gov.uk/ government/uploads/system/uploads/attachment_data/file/888254/ COVID19_Epidemiological_Summary_w22_Final.pdf

4 Russell P. New coronavirus: UK public health campaign Launched. Medscape, 2020.

5 Department of Health and Social Care. Coronavirus (COVID-19) action plan, 2020. Available: https://www.gov.uk/government/ publications/coronavirus-action-plan

6 UK Government. PM statement on coronavirus, 2020. Available: https://www.gov.uk/government/speeches/pm-statement-oncoronavirus-16-march-2020 [Accessed 16 Mar 2020].

7 Ferguson NM, Laydon D, Nedjati-Gilani G. Impact of nonpharmaceutical interventions (NPIs) to reduce COVID19 mortality and healthcare demand, 2020.

8 Cowling BJ, Ng DMW, Ip DKM, et al. Community psychological and behavioral responses through the first wave of the 2009 influenza $\mathrm{A}(\mathrm{H} 1 \mathrm{N1}$ ) pandemic in Hong Kong. J Infect Dis 2010;202:867-76.
9 Agüero F, Adell MN, Pérez Giménez A, et al. Adoption of preventive measures during and after the 2009 influenza $A(H 1 N 1)$ virus pandemic peak in Spain. Prev Med 2011;53:203-6.

10 Rubin GJ, Amlôt R, Page L, et al. Public perceptions, anxiety, and behaviour change in relation to the swine flu outbreak: cross sectional telephone survey. BMJ 2009;339:b2651.

11 Rubin GJ, Potts HWW, Michie S. The impact of communications about swine flu (influenza A H1N1v) on public responses to the outbreak: results from 36 national telephone surveys in the UK. Health Technol Assess 2010;14:183-266.

12 Lau JTF, Griffiths S, Choi KC, et al. Avoidance behaviors and negative psychological responses in the general population in the initial stage of the $\mathrm{H} 1 \mathrm{~N} 1$ pandemic in Hong Kong. BMC Infect Dis 2010;10:139.

13 Eastwood K, Durrheim D, Francis JL, et al. Knowledge about pandemic influenza and compliance with containment measures among Australians. Bull World Health Organ 2009;87:588-94.

14 Lohiniva A-L, Sane J, Sibenberg K, et al. Understanding coronavirus disease (COVID-19) risk perceptions among the public to enhance risk communication efforts: a practical approach for outbreaks, Finland, February 2020. Euro Surveill 2020;25.

15 Gesser-Edelsburg A, Cohen R, Hijazi R, et al. Analysis of public perception of the Israeli government's early emergency instructions regarding COVID-19: online survey study. J Med Internet Res 2020;22:e19370.

16 Olapegba PO, Ayandele O. Survey data of COVID-19-related knowledge, risk perceptions and precautionary behavior among Nigerians. Data Brief 2020;8:105685.

17 Motta Zanin G, Gentile E, Parisi A, et al. A preliminary evaluation of the public risk perception related to the COVID-19 health emergency in Italy. Int J Environ Res Public Health 2020;17 doi:10.3390/ ijerph17093024

18 Kwok KO, Li KK, Chan $\mathrm{HHH}$, et al. Community responses during early phase of COVID-19 epidemic, Hong Kong. Emerg Infect Dis 2020;26:1575-9.

19 McFadden SM, Malik AA, Aguolu OG, et al. Perceptions of the adult US population regarding the novel coronavirus outbreak. PLoS One 2020:15:e0231808.

20 Husnayain A, Shim E, Fuad A, et al. Understanding the community risk perceptions of the COVID-19 outbreak in South Korea: Infodemiology study. J Med Internet Res 2020;22:e19788.

21 Atchison CJ, Bowman L, Eaton JW. Report 10: public response to UK government recommendations on COVID-19: population survey, 17-18 March 2020, 2020.

22 YouGov. ESOMAR28: 28 questions to help online research buyers. Available: http://doc.ukdataservice.ac.uk/doc/7647/mrdoc/pdf/7647 methodology_esomar_28.pdf [Accessed 14 Mar 2020].

23 Office for National Statistics. UK 2011 census data. Available: https://www.ons.gov.uk/census/2011census

24 Kwok KO, KK L, Chan $\mathrm{HHH}$. Community responses during the early phase of the COVID-19 epidemic in Hong Kong: risk perception information exposure and preventive measures. medRxiv 2020.

25 Fenton K, Pawson E, de Souza-Thomas L. Beyond the data: understanding the impact of COVID-19 on BamE communities. PHE. online report, 2020. Available: https://assets.publishing.service.gov.uk/ government/uploads/system/uploads/attachment_data/file/892376/ COVID_stakeholder_engagement_synthesis_beyond_the_data.pdf

26 Ranganathan P, Pramesh CS, Aggarwal R. Common pitfalls in statistical analysis: logistic regression. Perspect Clin Res 2017;8:148-51.

27 Rothman KJ. No adjustments are needed for multiple comparisons. Epidemiology 1990;1:43-6.

28 Feise RJ. Do multiple outcome measures require $\mathrm{p}$-value adjustment? BMC Med Res Methodol 2002;2:8.

29 Bults M, Beaujean DJMA, Richardus JH, et al. Perceptions and behavioral responses of the general public during the 2009 influenza A (H1N1) pandemic: a systematic review. Disaster Med Public Health Prep 2015;9:207-19.

30 Ahmed F, Zviedrite N, Uzicanin A. Effectiveness of workplace social distancing measures in reducing influenza transmission: a systematic review. BMC Public Health 2018;18:518.

31 Goodwin R, Sun S. Public perceptions and reactions to H7N9 in Mainland China. J Infect 2013;67:458-62.

32 Jang WM, Cho S, Jang DH, et al. Preventive behavioral responses to the 2015 middle East respiratory syndrome coronavirus outbreak in Korea. Int J Environ Res Public Health 2019;16:ijerph16122161.

33 UK_Government. Support for those affected by Covid-19, 2020. Available: https://www.gov.uk/government/publications/support-forthose-affected-by-covid-19 